\title{
STUDENT HEAVY WORK INVESTMENT, BURNOUT, AND THEIR ANTEGEDENTS: THE GASE OF SERBIA
}

\author{
Sonja Ivancevic ${ }^{1}$, Tatjana Ivanovic ${ }^{2}$, Milica Maricic ${ }^{3}$ and Mladen Cudanov ${ }^{4 *}$ \\ ${ }^{122) 344)}$ University of Belgrade, Belgrade, Serbia
}

\section{Please cite this article as:}

Ivancevic, S., Ivanovic, T., Maricic, M. and Cudanov, M., 2020. Student Heavy Work Investment, Burnout, and Their Antecedents: The Case of Serbia. Amfiteatru Economic, 22(Special Issue No. 14), pp. 1182-1205.

\section{Article History}

Received: 23 June 2020

Revised: 12 August 2020

Accepted: 16 September 2020

\begin{abstract}
The objective of this study is to propose a model including antecedents of student Heavy Work Investment (HWI) and burnout based on the model developed by Snir and Harpaz (2012). Our data source was the survey of 1,640 students of the University of Belgrade. Student HWI is evaluated through its two dimensions, time commitment and work intensity, and student burnout through its four dimensions: personal, studies-related, teachers-related and colleagues-related burnout. The antecedents or predictor variables are chosen in the wake of prior research, being categorised into three groups internal/dispositional (student work engagement), external/situational (perceived course load, tuition payment source and achievement-related family pressure) and background (gender). The effect of HWI on student burnout is also examined. Our results are synthesized in a holistic model showing the direct effect of HWI-TC (time commitment) on HWI-WI (work intensity). Tuition payment source is shown to be the only common predictor for all the examined constructs, and HWI is shown to have negative consequences on all four dimensions of burnout. Eight model validity indices confirm the validity of the proposed model. In conclusion, our results can be used to develop the academic programmes with optimal estimated work investment, diminishing the chance of student burnout by calibrating work intensity and work engagement.
\end{abstract}

Keywords: HWI, burnout, work engagement, work investment, time commitment, student

JEL Classification: M12, M54, M 59, O15

\footnotetext{
* Corresponding author, Mladen Cudanov - e-mail: mladen.cudanov@ fon.bg.ac.rs
} 


\section{Introduction}

Heavy work investment (HWI) has been researched through workaholism since the seventies. Nevertheless, a new concept that defines HWI as a construct which consists of two dimensions - work intensity (HWI-WI) and time commitment (HWI-TC) - has been examined in the second decade of the twenty-first century (Harpaz and Snir, 2016; Rabenu et al., 2019).

The latter studies investigated the predictors of HWI: internal/dispositional, external/situational, and background ones (Snir and Harpaz, 2012, 2015), but also the positive and negative outcomes of HWI, among which are work satisfaction and burnout (Beek et al., 2013). So far, the two-dimensional model of HWI has been tested in the organisational context only, and it has not been examined in the academic environment.

In contrast, students' well-being has been examined for decades, for it is considered to be one of the most desirable results of instruction and learning processes (Paloș, Maricuţoiu and Costea, 2019). Students' well-being has most commonly been measured through student burnout and student engagement, as its undesired and desired manifestations (Upadyaya and Salmela-Aro, 2013). Burnout syndrome is defined as a state of the utmost emotional, psychological and physical exhaustion stemming from the prolonged stress in either work or academic environment, and is assigned a diagnosis F 43.2 (Ivancevic, Vaci and Nisic, 2016). In contrast, work engagement (WE) is described as its antipode, depicting a positive, fulfilling and a constructive state of mind related to work (Schaufeli et al., 2002). As burnout is confirmed to be among the negative outcomes of employees' HWI, it is of the uttermost importance to determine if this severe health disorder may also be a consequence of student HWI, and whether work engagement is the antecedent of each of the constructs (Dogan, 2015). Moreover, the relevant literature in the field suggests that there are other common predictors of employees' HWI and academic burnout, such as financial strains, workload, external pressures and gender, whose examination can provide a better insight into HWI and burnout dynamics and occurrence (Mastenbroek et al., 2014; Adams, Mayers and Beidas, 2016; Stoddard, Urban and Schmeiser, 2018).

With this background, our study aims to configure a model consisting of student HWI (including HWI-TC and HWI-WI), student burnout and their internal (work engagement), situational (course load, achievement-related family pressure and tuition payment source) and background (gender) antecedents. The results of the study should provide the answers to the following research questions a) 'Which internal, situational and background factors are the antecedents of student HWI-WI and HWI-TC?' b) 'Which internal, situational and background factors are the antecedents of student burnout?' c) 'Do HWI components predict student burnout?' and d) 'Does HWI-TC have an impact on HWI-WI?'.

These findings should make a contribution to both literature and practice, providing the foundation for future research regarding student HWI as well as the guidelines for the creation of student burnout prevention programs. 


\section{Literature review}

\subsection{Heavy-Work Investment (HWI)}

The concept of heavy work investment (HWI) represents a relatively new phenomenon and the academic literature in this field is still scarce (e.g. Rabenu and Aharoni-Goldenberg, 2017; Babic et al., 2019; Van Beek et al., 2013; Astakhova and Hogue, 2013; Rabenu et al., 2019; Houlfort et al., 2014; Harpaz and Snir, 2016; Schaufeli, 2016; Taris, Van Beek and Schaufeli, 2015).

In the HWI model introduced by Snir and Harpaz (2012), time commitment (HWI-TC) refers to the devotion of time in work (to work long hours), while work intensity (HWI-WI) refers to the effort invested in work (Snir and Harpaz, 2015), or "the intensity of mental and/or physical exertion during working time" (Green, 2008, p. 116). Therefore, an individual needs to score high on each dimension of HWI to be considered a heavy work investor, i.e. he/she should not only work long hours but also put substantial effort and energy in their work.

The predictors of HWI include various background, external and internal variables. Background variables include gender, educational level, parenthood; external predictors of HWI include basic financial needs, specific work requirements, employer/manager requirements, organisational culture (particularly, if it promotes praxes such as working overtime) and workload (Harpaz and Snir, 2015); internal variables include individual differences - work motivation, passion to work, work ethic, work engagement, and the like. (Snir and Harpaz, 2012, 2015). The authors of this concept defined two types of HWI based on the individual's motives - situational HWI (which is connected to external predictors) and dispositional HWI (which is connected to internal predictors) (Houlfort et al., 2014). HWI may lead to different positive or harmful consequences, both for the employees and the organisation (Houlfort et al., 2014). The outcomes of HWI may include health issues (Astakhova and Hogue, 2013; Schaufeli et al., 2009), work-to-family conflicts, satisfaction at work and productivity (Rabenu et al, 2019).

This study aims to determine which internal, situational and background factors are the antecedents of student HWI-WI and HWI-TC; it also aims to determine if student HWI-TC has an impact on HWI-WI.

\subsection{Student burnout}

Introduced into psychology by Freudenberger (1974), burnout syndrome was described as a reaction to incessant stress in the workplace, manifested through a gradual loss of energy, idealism, and the sense of purpose, and was firstly thought to be experienced by the helping professions only. Following research, primarily that of Christina Maslach and her associates, linked burnout to a great variety of emotional, physical and psychological impairments, such as depression (Salmela-Aro, Savolainen and Holopainen, 2009), utter exhaustion, insomnia, social dysfunction, conflicts and elevated usage of alcohol and drugs, family issues and other (Maslach, et al., 1997). Simultaneously, researchers proved that burnout can be experienced in all jobs and professions (Ivanović, Ivancevic and Maricic, 2020), and that it is also experienced by college students (Jacobs and Dodd, 2003; Carlotto, Nakamura, and Camara, 2006; Balogun et al., 1996). Literature shows that theoretical bases of academic burnout and job burnout correspond (Schaufeli et al., 2002; Yang and Farn, 
2005), often defining student burnout as "a psychological syndrome that occurs due to chronic academic stress and course loads, manifested as emotional exhaustion because of study demands, a cynical and detached attitude toward schoolwork, and a reduced efficacy as a student" (Shin, 2012, p. 287).

A number of specific factors influencing students in the learning process have been examined in regard to burnout (Yang and Farn, 2005). The following factors are all found to have a positive correlation with student burnout: the competitive climate created among students, supervisors and teachers (Balogun et al., 1996), the pressures regarding the studies' financing (Marôco and Tecedeiro, 2009), excessive course load and the time invested in studying that diminishes the time necessary for students' personal needs and leisure (Nogueira-Martins, 2004) as well as the high amount of effort invested but not rewarded properly (Williams, Dziurawiec, and Heritage, 2018). Along with examining burnout predictors, researchers found additional negative outcomes of student burnout, such as lessened motivation to perform demanded faculty obligations, increased absenteeism from classes and even higher percentage of university drop out (Ramist, 1981). These only confirm the need for early burnout detection as well as the identification of burnout-causing factors in a specific academic context, so that adequate interventions and support could be provided to the endangered groups of students (Campos, Carlotto and Maroco, 2013).

This study aims to determine which internal, situational and background factors are the antecedents of student burnout; it also aims to determine if HWI components predict student burnout.

\subsection{Internal antecedent: Work engagement}

Work engagement (WE) is an internal predictor of HWI (Taris, Van Beek and Schaufeli, 2015). Work engagement denotes "a positive, fulfilling, work related state of mind that is characterised by vigour, dedication, and absorption" (Schaufeli et al. 2002, p.74). It indicates high involvement with work (Di Stefano and Gaudiino, 2019), thus representing a construct of HWI (Salanova et al., 2014). Unlike workaholism, as another examined construct of HWI, work engagement has been traditionally viewed as a "good" form of HWI (Schaufeli, 2016; van Beek, Taris, and Schaufeli, 2011; Astakhova and Hogue, 2013; Taris, Van Beek, and Schaufeli, 2015; Babic et al., 2019) or its healthy side (Di Stefano and Gaudiino, 2019). It is connected only to positive aspects of hard work, which have beneficial effects on one's well-being (Shimazu, Schaufeli, Kamiyama, and Kawakami, 2015), physical and mental health (Schaufeli, 2016), job satisfaction (van Beek et al., 2013) and life satisfaction (Schaufeli and Salanova, 2007).

There are various studies investigating the engagement of students in different study levels (Schaufeli et al., 2002; Salanova et al., 2010). Engagement denotes that students are actively involved in their tasks or given activities (e.g., Case, 2008), and the engaged students are distinguished by high-level energy and mental toughness (Schaufeli et al., 2002). They succeed in separating their private life from their studies and find time for leisure activities (Schaufeli et al., 2002) being able to fully disengage from their study activities (Van Beek, 2014). In the research on students, phrases work and academic engagement have been used synonymously (Carmona-Halty, Schaufeli and Salanova, 2019).

Vol. $22 \cdot$ Special Issue No. $14 \cdot$ November 2020 
Work engagement was frequently examined in relation to burnout and often described as its positive antithesis (Maslach et al., 2001). It was also a recurrent variable in the research investigating student burnout in particular (Shin, 2012; Palos, Maricuţoiu and Costea, 2019), frequently treated as an eroded facet of work engagement (Maslach and Leiter, 1997). It was also examined in relation to academic performance (Palos, Maricuţoiu and Costea, 2019), and students' satisfaction (Gray and DiLoreto, 2016).

In their empirical research Rabenu et al. (2019) confirmed a positive relation between work engagement and HWI, finding that WE is a significant predictor of HWI. They determined positive relations both between WE and HWI-TC as well as between WE and HWI-WI.

This study aims to test the effect of work engagement on student HWI-TC and HWI-WI as well as its effect on student burnout.

\subsection{External/situational antecedents: Course load (Workload)}

Workload represents a common work-related stressor (Bakker and Demerouti, 2014) and refers to excessive volume of work (Harpaz and Snir, 2015) that can drain individuals' energy (Schaufeli and Bakker, 2004). Examining workload, Kahn et al. (1964) explained that individuals feel overloaded when they need to solve a large number of problems within a restricted time interval, while Maslach and Leiter (1997) confirmed that it encompasses both time and energy. It consequently affects their health, increases dissatisfaction, anger, nervousness, tension, sense of failure and the like (Cobb and Rose, 1973). According to COR (Conservation of Resources) theory, workload is among the crucial external factors impacting burnout (Yang, 2004), whereas it is also proven to be one of HWI's external predictors (Snir and Harpaz, 2015).

Some studies have demonstrated that workload/course load is positively connected only to some dimensions of burnout (Male and May, 1998), while other have found that it is connected to all dimensions of burnout (Greenglass, Burke and Fikensbaum, 2001). Regardless, researchers emphasise that objective (absolute) workload is not always the right thing to be tested in regard to burnout; they state that it is a subjective response to workload that should be taken into account and explored as a burnout antecedent (Jackobs and Dodd, 2003), or, in other words, one's own perception of it.

This study aims to test the effect of the perceived workload on student HWI-TC and HWIWI as well as the effect of the perceived workload on student burnout.

\subsection{External/situational antecedents: Achievement-related family pressure}

In many societies, academic success is instrumental in climbing the social ladder (Cheng and Selden, 1994). Thus, a number of students are faced with enormous pressure from their families to obtain outstanding results all the way through their schooling years, from elementary school to university (Shin et al., 2012). In some societies, these pressures are even more extreme for their cultural norms (Isralowitz and Hong, 1990; Huan, Yeo, Ang, and Chong, 2006). However, achievement-related family pressure has been proven to result in a number of mental-health issues, like delinquency, depression, suicidal behaviour (Ang and Huan 2006; Eremsoy et al. 2005) and burnout (Moneta, 2011), all stemming from the 
incongruity between students' resources and the expectations of success (Salanova et al., 2010)

This study aims to test the effect of the perceived achievement-related family pressure on student HWI-TC and HWI-WI as well as the effect of this pressure on student burnout.

\subsection{External/situational antecedents: Tuition payment source}

Personal economic constraints have been examined as another possible external predictor of HWI. In addition, the relations between student financial circumstances and their academic advancement as well as academic stress and stress-related problems have been examined (Adams, Mayers and Beidas, 2016). The results show that a financial strain, usually described as an experienced economic stress and deficiency of economic support, is one of the major stressors affecting students' progress and performance, and is even linked to the probability of students' graduation (Bowen, Chingos and McPherson, 2009). In addition, it is shown to deteriorate students' physical and mental health (Byrd and McKinney, 2012; Dusselier et al.2005), causing stress, depression and suicidal ideation (Kisch, Leino and Silverman, 2005). This can lead us to believe that student burnout, which is a result of chronic stress (Shin, 2012), can also be linked to the undesirable financial circumstances of students.

The effects of financial strains have been examined through the income level of students' families (Adams, Mayers and Beidas, 2016) or through the ways students finance their studies.

This study aims to examine the effects of students' tuition payment source on student HWI-TC, HWI-WI and burnout.

\subsection{Background antecedent: Gender}

Gender has been examined as a possible HWI background predictor (Snir and Harpaz, 2012, 2015), but has also been associated to psychological well-being and academic success (Mastenbroek et al., 2014). The role of gender as one of the potential factors impacting burnout was suggested by Maslach et al. (1996), with later research suggesting that gender does affect certain components of burnout but not necessarily overall burnout (Mastenbroek et al., 2014). In addition, studies examining academic success show it to be more important to female than to male students (Murberg and Bru, 2004), while fearing to fail academically and worrying that they would not meet high achievement criteria contribute to the increased level of academic burnout in female students (Kiuru et al., 2008). These findings are congruent with those showing that female students experience increased level of stress (Jose and Ratcliffe, 2004), and those that associate male students with fewer indications of distress, depression and anxiety (Mastenbroek et al., 2014).

This study aims to investigate the relation between students' gender and student HWI-TC, HWI-WI and burnout. 


\section{Proposed conceptual model}

The model we herein propose conceptualised as in figure no. 1 was driven by the theory of Snir and Harpaz (2012, 2015) and Taris, Van Beek and Schaufeli (2015).

As mentioned, HWI as the two-dimensional concept has not been examined in the academic environment with students as a target group so far. However, having in mind that university studies highly resemble work (Salanova et al., 2010), the activities of students and employees may be regarded as equivalent (Van Beek, 2014). Thus, we attempted to investigate the following as the potential predictors of student HWI and student burnout: internal predictors - work engagement (Taris, Van Beek and Schaufeli, 2015), external/situational predictors - workload (perceived course load), tuition payment source (Snir and Harpaz, 2012, 2015) and achievement-related family pressure, and a background predictor - gender (Snir and Harpaz, 2012, 2015). We also examined the impact of the HWI-WI / HWI-TC on student burnout.

In order to provide an in-depth analysis of the impact of internal, situational, and background antecedents, and HWI components on student burnout, we observed their impact on each individual burnout scale, led by the example of a number of researchers (Lingard, 2003; Hastings and Bham, 2003). Such an approach could be beneficial as it might show that different predictors have different impacts on individual burnout scales, thus shedding additional light on the topic of students' burnout. Lastly, the model examines the influence of HWI-TC on HWI-WI since previous studies suggested the relationship between the two variables (Fiksenbaum et al., 2010; Rabenu and Aharoni-Goldenberg, 2017).

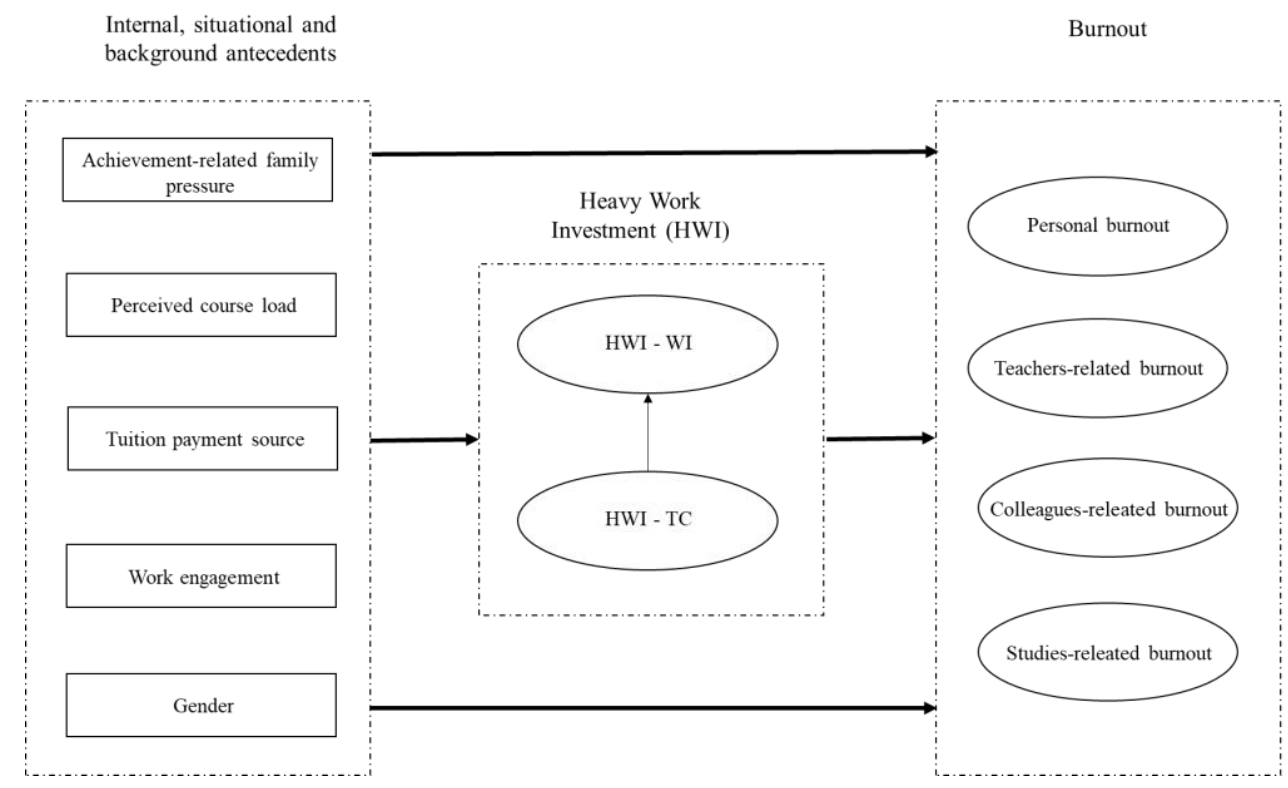

Figure no. 1. Proposed conceptual model 
Accordingly, our research questions can be formulated as:

1. Which internal, situational and background factors are the antecedents of student HWI-WI and HWI-TC?

2. Which internal, situational and background factors are the antecedents of student burnout?

3. Do HWI components predict student burnout?

4. Does HWI-TC have an impact on HWI-WI?

\section{Research methodology}

In order to test the validity of the proposed conceptual model and to test the devised hypothesis, we employed the structural equation modelling (SEM) analysis. SEM analysis can be classified as a multivariate statistical analysis which is based on the foundations and principles of factor analysis and regression analysis (Asparouhov and Muthén, 2009; Kline, 2005). The analysis serves in two directions. First, it reduces the dimensionality of the observed phenomenon, while, secondly, it provides insights into the relationship between the newly formed, latent variables or constructs. Taking into account the benefits of the SEM analysis, the clear theoretical concept it is based on, and the various software solutions which enable its application, this analysis has become a vastly used statistical approach for verifying conceptual models (Browne and Cudeck, 1993; Marsh et al., 2009).

So far, SEM analysis has been employed to test various conceptual models which encompass HWI-TC, HWI-WI, burnout, and different situational/demographic variables. Rabenu et al. (2019) explored how job engagement and managerial role directly impact burnout and the moderating effect of HWI-TC and HWI-WI among employees in America and Israel. Modelled the effect of workaholism, job engagement, workload, and financial needs through TC and WI on burnout of employees in Romania. Richards et al. (2016) modelled depersonalisation, emotional exhaustion, and reduced personal accomplishment measured on MBI scale using SEM analysis and role overload, role conflict, and role ambiguity as predictors. McNamara et al. (2011) created a conceptual model which models WI with job security, employment status, excessive hours, and low hours control and the impact of WI on work-life conflict and interpersonal conflict among hotel workers in Australia. Led by the example of the selected papers, we applied SEM to test our conceptual model.

To verify the proposed conceptual model, we designed a questionnaire which comprised of several sections presented in detail in the following paragraphs. The survey was conducted from October till December 2019 and it included Belgrade University students from all the faculty categories (http://www.bg.ac.rs/): Faculty of Law, Faculty of Pharmacy, Faculty of Biology, Faculty of Electrical Engineering, Faculty of Organizational Sciences information system and technology department, Faculty of Philosophy, and Faculty of Philology. The online questionnaire was distributed to the students with the help of the academic staff working at the chosen faculties, and the students completed the survey on the spot with the use of their mobile phones, in the presence of their professors or lecturers. After conducting the survey, the statistical analysis was performed using SPSS 25 while the SEM analysis was done using AMOS 22. 
Student burnout. A number of scales are used for student burnout measurement, with Maslach Burnout Inventory Student Survey (MBI-SS) being the most widely used. Nevertheless, for the purpose of this study, a slightly newer scale was used - the students version of Copenhagen Burnout Inventory (CBI-S). The original scale was developed in 2005 by Kristensen et al. (2005), while its students' version was later developed and validated by Portuguese authors (Campos, Carlotto and Maroco, 2013).

Heavy work investment ('time' and 'effort'). A difficulty regarding the measurement of student HWI was that two-dimensional student HWI had not been measured before, to our knowledge. In addition, the tool proposed by Snir and Harpaz (2012) for employees' HWI measurement was not found to be applicable to students' population. For instance, for measuring time commitment, the tool includes the questions connected to employees' working time in the workplace, which is not applicable since there are no determined 'working hours' for studying as there are for jobs. Also, employees are asked to compare the time they invest in work to their colleagues', but asking students to compare the hours they dedicate to studying to their peers' (or even to write the approximate number of hours they study) might not be relevant since it is a subjective feeling of what students experience as long. For those reasons, we simply asked the students to rate their tendency to study long on a seven-point frequency rating scale varying from 0 (never) to 6 (always). On the other hand, to measure student HWI-WI, we used a three-item scale, measuring their tendency to strive as hard as they can to be successful in their studies no matter the circumstances, their tendency to devote their full capacity to the subject they are studying and the frequency of the situations when they find it difficult to distance themselves from studying. The items were measured on the same seven-point frequency rating scale.

Work (Academic) engagement. The academic engagement has been measured by employing The Utrecht Work Engagement Scale for Students (UWES-9S) (CarmonaHalty, Schaufeli and Salanova, 2019). The UWES-9S has nine items within three subscales: Vigour, Dedication and Absorption. Items are scored on a seven-point frequency rating scale varying from 0 (never) to 6 (always).

Workload (Course load). Following the example of Jacobs and Dodd (2003) who suggested that subjective response to workload should be measured and investigated as a predictor of burnout, we took into account student own perception of course load and asked them to express it on a seven-point rating scale varying from 1 (low) to 7 (high). Other authors also used the one-item scale to measure students' perception of course load and test its effects on a number of variables (e.g. Sansgiry and Sail, 2006; Özdemir and Demir, 2019).

Tuition payment source. Students were asked to choose the option which describes the way they finance their studies: -from the budget of the Republic of Serbia, -self-financed, -cofinanced (meaning that a part of their tuition fee is financed from the state budget and a part they pay themselves) or -have other sources of financing studies (scholarships and loans).

Achievement-related family pressure. In order to measure the perceived family/parental pressure, students were asked to rate the pressure they feel their families/parents put on them in regard to their academic achievement (high GPA expectations and/or expectations of finishing the studies fast) on a seven-point rating scale varying from 1 (low) to 7 (high). Other authors also used a one-item scale to measure family/parental pressure in relation to burnout (e.g. Anderson and Cole, 1988). 


\section{Results}

\subsection{Sample characteristics}

The sample consisted of 1,640 students of the University of Belgrade. It included 1,193 female respondents who make $72.7 \%$ of the sample and 447 male respondents who make $23.7 \%$. A disproportion in the respondents' gender can be observed. In a way, such a proportion was expected having in mind that the University of Belgrade has more female students (University of Belgrade, 2020). When it comes to the age of respondents, the mean age is 22.00 with the standard deviation of 2.369. The youngest respondent was 18 , while the oldest, a PhD student, was 52. The median age of respondents is 22.00 .

Tuitions are covered financed from the budget of the Republic of Serbia for $64.1 \%$ of the respondents, followed by $34.2 \%$ who are self-financed. The rest are co-financed or have other sources of financing the studies. Most of the respondents do not study in their home towns $(58.4 \%)$.

\subsection{Validation of the proposed conceptual model}

The initial step in the SEM analysis is to inspect the internal consistency of the proposed constructs. The suggested metrics for assessing the internal consistency and scale reliability are Cronbach's alpha (Cronbach, 1951), Average Variance Extracted (AVE), and Composite Reliability (CR). Cronbach's alpha should be in the range from 0.70 to 0.95 (Tavakol and Dennick, 2011), AVE should be above 0.5, while for CR above 0.7 (Alarcón and Sánchez, 2015).

The calculated Cronbach's alpha, AVE, and CR per latent variable and the number of items per scale are given in table no. 1. The calculated metrics are above or marginally below the threshold, indicating that each of the proposed constructs measures a particular aspect and that the data are suitable for SEM analysis.

Table no. 1. Obtained Cronbach's alpha, AVE, and CR per construct and the number of items per construct

\begin{tabular}{|c|c|c|c|c|c|}
\hline & HWI-WI & $\begin{array}{c}\text { Personal } \\
\text { burnout }\end{array}$ & $\begin{array}{c}\text { Teachers- } \\
\text { related } \\
\text { burnout }\end{array}$ & $\begin{array}{c}\text { Colleagues- } \\
\text { related } \\
\text { burnout }\end{array}$ & $\begin{array}{c}\text { Studies-related } \\
\text { burnout }\end{array}$ \\
\hline $\begin{array}{c}\text { No. of } \\
\text { items }\end{array}$ & 3 & 6 & 6 & 6 & 7 \\
\hline Alpha & 0.730 & 0.906 & 0.933 & 0.926 & 0.836 \\
\hline AVE & 0.650 & 0.688 & 0.750 & 0.738 & 0.590 \\
\hline CR & 0.847 & 0.929 & 0.947 & 0.943 & 0.889 \\
\hline
\end{tabular}

Additionally, we explored the common method bias using Harman's one factor test. The one factor model explains $32.849 \%$ of variance, which is significantly below the $50.00 \%$ threshold. Therefore, there is no CMB and we conclude that variations in responses are not caused by the instrument rather than the actual predispositions of the respondents that the instrument attempts to uncover (Podsakoff et al., 2003). 
The initial model had relatively poor fit to the data (Chi-square $=4951.369$, df $=493$, $\mathrm{p}<0.000, \mathrm{RMSEA}=0.074, \mathrm{CFI}=0.882$, TLI=0.866). To evaluate the significance of the paths and indicators, we employed critical ratios (C.R.). Namely, the value of C.R. above 1.96 or below -1.96 signalises a two-sided significance at the 5\% level (Hox and Bechger, 1998). Paths between situational variables and HWI-WI, HWI-TC, and different burnout dimensions which had C.R. below the defined threshold were removed from the model. Additionally, modification indices were used to fine-tune our model. Only statistically significant paths were retained. Also, paths with weak impact, with standardised coefficient below 0.5 in absolute values, were left in the model since the goal was to obtain a good measurement model (Allen et al., 2019; Milenković, Glavić, and Maričić, 2019).

The in-depth analysis of the final model shows that the model had a relatively good fit to the data. The general adequacy of the proposed SEM model has been evaluated using absolute fit indices, comparative fit indices, and parsimonious fit indices (Table no. 2). The absolute fit indices are presented with chi-square, adjusted goodness-of-fit index (AGFI), and root-mean-square-error-of-approximation (RMSEA). The results demonstrate that two of these indices are marginally below the threshold (Hsu, 2013). The comparative indexes, Comparative Fit Index (CFI) and Tucker-Lewis index (TLI) are also acceptable or marginally acceptable. The parsimonious indexes the Parsimony Goodness-of-Fit Index (PGFI) and the Parsimonious Normed Fit Index (PNFI) are above the 0.5 threshold (Hsu, 2013). The standardized Root Mean Square Residual (SRMR) is also marginally above the defined threshold of 0.08 . Taking into account the model complexity, the sample size, and the acceptable and marginally acceptable values of indexes, we can conclude that the final model has a solid fit (Hooper, Coughlan, and Mullen, 2008; Hox and Bechger, 1998). The assessment of the final model is given in table no. 3 .

Table no. 2. Cut-off criteria for several fit indices (based on Hsu (2013)), the index values of the final model, and model fit

\begin{tabular}{|l|l|l|l|}
\hline Index & $\begin{array}{l}\text { General rule for } \\
\text { acceptable fit }\end{array}$ & Value & Model fit \\
\hline$\chi^{2}$ & The smaller the better & $3682.180, \mathrm{df}=469$ & \\
\hline GFI & $>0.9$ & 0.928 & Yes \\
\hline AGFI & $>0.8$ & 0.859 & Yes \\
\hline RMSEA & $<0.05$ & 0.065 & Yes \\
\hline CFI & $>0.9$ & 0.915 & Marginally acceptable \\
\hline TLI & $>0.9$ & 0.899 & Marginally acceptable \\
\hline PGFI & $>0.5$ & 0.701 & Yes \\
\hline PNFI & $>0.5$ & 0.756 & Yes \\
\hline SRMR & $<0.08$ & 0.0916 & Marginally acceptable \\
\hline
\end{tabular}

We found that the construct HWI-WI has four predictors: achievement-related family pressure, perceived course load, tuition payment source, as well as HWI-TC. Student work engagement was not found to be a HWI-WI predictor, and neither was student gender. The absolute obtained standardised coefficients range from 0.089 (tuition payment source) to 0.577 (HWI-TC). The three situational variables have a statistically significant impact on HWI-WI meaning that the students who are under pressure from their families to have high GPAs or to finish studies fast, who perceive their course load to be heavy, and those who are funded from the state budget have higher work intensity. Also, as students' time 
commitment increases so does their work intensity. The R square of this construct is 0.427 , meaning that the four predictors explain $42.7 \%$ of the variability of HWI-WI, thus creating a moderate model.

Student HWI-TC has three predictors: student work engagement, perceived course load and tuition payment source. The absolute obtained standardised coefficients range from 0.078 (tuition payment source and perceived course load) to 0.662 (work engagement). As work engagement increases, the longer the student is ready to study. The two situational variables - perceived course load and tuition payment source - also have a statistically significant impact on HWI-TC meaning that the students who are under pressure from their families to have high GPAs or to finish studies fast and those who are funded from the state budget commit more time to their studies. The $\mathrm{R}$ square of this construct is 0.451 , meaning that the three predictors explain $45.1 \%$ of the variability of HWI-TC, thus creating a moderate model.

Personal burnout can be modelled using: student work engagement, HWI-WI, one situational variable - tuition payment source - and gender as a background variable. The obtained standardised coefficients in absolute values range from 0.082 (gender) to 0.949 (HWI-WI). The results indicate that personal burnout increases when the student work intensity increases, but on the other hand, decreases when student work engagement increases. Additionally, female, self-financed students have higher personal burnout. The R square of this construct is 0.798 , indicating that the four predictors explain $79.8 \%$ of the variability of personal burnout, thus forming a model of solid quality.

Teachers-related burnout has three predictors: work engagement, HWI-WI, and one situational variable - tuition payment source. The obtained standardised coefficients in absolute values range from 0.085 (tuition payment source) to 0.701 (HWI-WI). The results indicate that the teachers-related burnout increases when student work intensity increases, but on the other hand, decreases when student work engagement increases. Also, selffinanced students have higher teachers-related burnout. The R square of teachers-related burnout is 0.488 , telling us that the four predictors explain $48.8 \%$ of its variability, thus forming a model of moderate quality.

Colleagues-related burnout has the same three predictors as teacher-related burnout: work engagement, HWI-WI, and one situational variable - tuition payment source. The obtained standardised coefficients in absolute values range from 0.073 (tuition payment source) to 0.549 (HWI-WI). The results indicate that the colleagues-related burnout increases when student work intensity increases, but on the other hand, decreases when student work engagement increases. Self-financed students have slightly higher colleagues-related burnout. The $\mathrm{R}$ square of this construct is 0.252 , meaning that the three predictors explain $25.2 \%$ of the variability of colleagues-related burnout.

Studies-related burnout has four predictors: work engagement, HWI-WI, one situational variable - tuition payment source - and gender as a background variable. The obtained standardised coefficients in absolute values range from 0.030 (gender) to 0.999 (HWI-WI). The results indicate that the studies-related burnout increases when student work intensity increases, but on the other hand, decreases when student work engagement increases. Selffinanced female students have a slightly higher studies-related burnout. The $\mathrm{R}$ square of studies-related burnout is 0.986 , showing that the four predictors explain $98.6 \%$ of the construct variability, thus forming a model of high quality. 
Table no. 3. Assessment of the model: construct, predictors, obtained standardised coefficients, C.R., and the $R$ square

\begin{tabular}{|c|c|c|c|c|}
\hline Construct & Predictors & Std Coeff & C.R. & $\mathbf{R}^{2}$ \\
\hline \multirow{4}{*}{ HWI-WI } & $\begin{array}{c}\text { Achievement-related family } \\
\text { pressure }\end{array}$ & $0.100^{* *}$ & 4.687 & \multirow{4}{*}{0.427} \\
\hline & HWI-TC & $0.577^{* *}$ & 10.826 & \\
\hline & Perceived course load & $0.221^{* *}$ & 8.201 & \\
\hline & Tuition payment source & $-0.089^{* *}$ & -2.897 & \\
\hline \multirow{3}{*}{ HWI-TC } & Work engagement & $0.662^{* *}$ & 36.408 & \multirow{3}{*}{0.451} \\
\hline & Tuition payment source & $-0.078^{* *}$ & -4.292 & \\
\hline & Perceived course load & $0.078^{* *}$ & 4.263 & \\
\hline \multirow{4}{*}{ Personal burnout } & HWI-WI & $0.949^{* *}$ & 11.388 & \multirow{4}{*}{0.798} \\
\hline & Work engagement & $-0.545^{* *}$ & -20.956 & \\
\hline & Tuition payment source & $0.196^{* *}$ & 7.577 & \\
\hline & Gender & $0.082^{* * *}$ & 4.607 & \\
\hline \multirow{3}{*}{$\begin{array}{l}\text { Teachers-related } \\
\text { burnout }\end{array}$} & HWI-WI & $0.701^{* * *}$ & 11.167 & \multirow{3}{*}{0.488} \\
\hline & Work engagement & $-0.545^{* *}$ & -21.690 & \\
\hline & Tuition payment source & $0.085^{* *}$ & 3.444 & \\
\hline \multirow{3}{*}{$\begin{array}{l}\text { Colleagues- } \\
\text { related burnout }\end{array}$} & HWI-WI & $0.549^{* *}$ & 10.324 & \multirow{3}{*}{0.252} \\
\hline & Work engagement & $-0.208^{* *}$ & -7.839 & \\
\hline & Tuition payment source & $0.073^{* *}$ & 2.808 & \\
\hline \multirow{4}{*}{$\begin{array}{l}\text { Studies-related } \\
\text { burnout }\end{array}$} & HWI-WI & $0.999^{* *}$ & 11.625 & \multirow{4}{*}{0.986} \\
\hline & Work engagement & $-0.736^{* *}$ & -29.711 & \\
\hline & Tuition payment source & $0.196^{* *}$ & 7.765 & \\
\hline & Gender & $0.030^{*}$ & 2.052 & \\
\hline
\end{tabular}

Notes: ${ }^{*} \mathrm{p}<0.05,{ }^{* *} \mathrm{p}<0.01$

Since student HWI-TC was shown to have a direct effect on student HWI-WI and no direct effect on student burnout, we strived to explore the indirect effect of student HWI-TC on burnout (Table no. 4). Preacher and Hayes (2008) define standardised indirect effects as 'indexes of mediation' and suggest testing their significance using bootstrap. Accordingly, we performed 1000 bootstrap samples. All presented indirect effects are significant at the level of 0.01. HWI-TC proved to have a positive, statistically significant indirect effect on all four burnout scales. The standardised indirect coefficient ranges from 0.316 (on colleagues-related burnout) to 0.585 (on studies-related burnout). The obtained indirect coefficients are moderate strength indicating that the more time the students commit to studying, the more prone to burnout they will be.

Table no. 4. Path of the indirect effects of HWI-TC, standardised indirect coefficient, and the lower and upper bound of the $95 \%$ bootstrap confidence interval

\begin{tabular}{|l|c|c|c|}
\hline \multicolumn{1}{|c|}{ Path } & $\begin{array}{c}\text { Std. } \\
\text { indirect } \\
\text { coefficient }\end{array}$ & $\begin{array}{c}\text { Lower } \\
\text { bound of } \\
\text { the 95\% CI }\end{array}$ & $\begin{array}{c}\text { Upper } \\
\text { bound of } \\
\text { the 95\% } \\
\text { CI }\end{array}$ \\
\hline $\mathrm{HWI}-\mathrm{TC} \rightarrow \mathrm{HWI}-\mathrm{WI} \rightarrow$ Personal burnout & 0.547 & 0.498 & 0.598 \\
\hline $\mathrm{HWI}-\mathrm{TC} \rightarrow \mathrm{HWI}-\mathrm{WI} \rightarrow$ Teachers-related burnout & 0.404 & 0.359 & 0.451 \\
\hline $\mathrm{HWI}-\mathrm{TC} \rightarrow \mathrm{HWI}-\mathrm{WI} \rightarrow$ Colleagues-related burnout & 0.316 & 0.272 & 0.364 \\
\hline $\mathrm{HWI}-\mathrm{TC} \rightarrow \mathrm{HWI}-\mathrm{WI} \rightarrow$ Studies-related burnout & 0.585 & 0.529 & 0.633 \\
\hline
\end{tabular}




\section{Discussion}

In the current study, we proposed and tested an integrated model of student heavy work investment, student burnout, and their antecedents. The findings are discussed hereafter.

Antecedents of student HWI-WI and HWI-TC. Of the tested antecedents, all three situational variables - perceived course load, tuition payment source and achievement-related family pressure - have been proven to have significant effects on student work intensity and the two of them - perceived course load and tuition payment source - on student time commitment. Also, student work engagement, the internal variable, has been proven to have a significant effect on student time commitment. The last-mentioned finding is in line with the studies identifying work engagement as an internal HWI predictor (Taris, Van Beek and Schaufeli, 2015; Rabenu et al., 2019). To explain this, Taris et al. (2015) stated that engaged workers are heavier time and effort work investors because they want to work (Schaufeli and Bakker, 2010) and they like and enjoy their work. This also applies to students regarding their HWI-TC. However, the explanation of why student work engagement affects only student HWI-TC and not their HWI-WI herein, lies in the possible multicollinearity of the scales and suggests that a different scale can be used in the future. In addition, our results regarding the situational factors are in line with the studies that identified workload and financial needs as situational HWI predictors (Snir and Harpaz, 2015). Our study confirms that students who feel that they have many study-related obligations invest more time and effort into fulfilling them than those who do not. Interestingly, students whose studies are funded from the state budget invest more time and effort into studying in comparison to other students, and the possible explanation on that account might be that they do not want to lose their finance-related 'status'. Finally, achievement-related family pressure has been proven to be connected only to student HWIWI and not to student HWI-TC, which shows that students who feel more of this kind of pressure study more intensively than those who do not (this kind of pressure being typical for Serbian society). Since HWI-WI influences work outcomes more than the length of time invested in work per se (Rabenu and Aharoni-Goldenberg, 2017), it is understandable why the first relation has been confirmed rather than the second. The last finding showing that HWI-TC influences HWI-WI is a very interesting insight, indicating that HWI-WI increases with the time spent on studying and confirms previous findings of the two constructs being correlated (Fiksenbaum et al., 2010).

Antecedents of student burnout. Of all the tested variables, student work engagement, HWIWI, tuition payment source and student gender are found to affect student personal burnout and studies-related burnout significantly, while the first three mentioned variables are also found to affect teachers-related as well as colleagues-related burnout. The first relation is congruent with a great number of studies confirming that work engagement is negatively correlated with student burnout (Shin, 2012; Palos, Maricuţoiu and Costea, 2019) and burnout in general (González-Romá et al., 2006; Snir and Harpaz 2015; Ivanovic, Ivancevic and Maricic, 2020). The more engaged students are, the more they appreciate and enjoy their studies (Van Beek et al., 2012), and the less burnout risk they are exposed to. Thus, this result is not surprising but utterly expected. The second relation that has been confirmed is that between student HWI-WI and all dimensions of burnout. This is in line with the previous research suggesting that the effort invested in studies positively influences students' well-being if it springs from intrinsic motivation, and negatively if it originates from external factors (Black and Deci, 2000; Levesque et al., 2004; Kusurkar et 
al., 2013). Since our results show that student HWI-WI predictors are only external, it is no surprise that HWI-WI negatively affects their well-being by increasing burnout. It also confirms the findings of Leiter and Maslach (2003) who state that heavy investment of effort can exhaust one's resources and lead to eventual burnout. On the other hand, only an indirect effect of HWI-TC via HWI-WI on all dimensions of student burnout has been found. Previous studies examining the relation between working long hours and burnout gave inconsistent results (Martini, Arfken and Balon, 2006; Schaufeli, Taris and van Rhenen, 2008), and our result is congruent with that of Rabenu and Aharoni-Goldenberg (2017) who concluded that the relation between working overtime and burnout depends on the degree of work investment (since employees may work long hours but with different work effort). Thirdly, the tuition payment source has shown to be related to all types of burnout with self-financing students being more prone to this damaging syndrome. This corresponds to the findings of the studies showing that financial strains negatively affect students' mental health and well-being (Adams, Mayers and Beidas, 2016; Johnson, 2019). Taking into account the economic situation in Serbia, it is not surprising that the students who pay for the studies themselves are more susceptible to burnout, which can be related to the increased turnover among new generations (Ivanovic and Ivancevic, 2019). Lastly, gender has been proved to affect personal and studies related burnout, with female students being more vulnerable in both cases. The impact of gender on the likelihood of burnout occurrence is ambiguous. There are studies showing equal burnout rates in both genders and there are those showing higher burnout rates in females, whereas general stress level is commonly shown to be higher in females (Maslach and Jackson, 1981; Bakker, Demerouti and Schaufeli, 2002; Backović et. al., 2012). Also, studies show that gender affects different burnout dimensions in males and females (Purvanova and Muros, 2010). Adequate teachers' encouragement towards students as well as students' mutual support correlate closely to lower levels of academic burnout (Jacobs and Dodd, 2003; Salmela-Aro et al., 2009), and we can conclude that in this respect both male and female Belgrade university students are in the same position, while interventions regarding personal and studies related burnout should be tailor-made to gender-based groups of students.

In accordance to the detailed analysis, the summarized answers to the research questions can be provided. The answer to the first research question 'Which internal, situational and background factors are the antecedents of student HWI-WI and HWI-TC?' is that only the three situational factors - perceived course load, tuition payment source and achievementrelated family pressure are statistically significantly related to HWI-WI, while the two situational factors - perceived course load and tuition payment source - as well as the internal factor - work engagement - are related to student HWI-TC. The answer to the second research question 'Which internal, situational and background factors are the antecedents of student burnout?' is that the internal factor - work engagement - as well as the situational factor - tuition payment source - are related to all four dimensions of student burnout, while two of those dimensions, Personal and Studies-related burnout, are also affected by the background variable - gender. The answer to the third question 'Do HWI components predict student burnout?' is that student HWI-WI directly predicts all dimensions of student burnout, while student HWI-TC does not have a direct, but only an indirect effect via HWI-WI on all student burnout dimensions. Finally, the answer to the fourth research question 'Does HWI-TC have an impact on HWI-WI?' is positive, since student HWI-TC does influence student HWI-WI. 


\section{Conclusions}

In order to determine whether student HWI is a good or bad phenomenon, we aimed to examine if student burnout (a severe health disorder) may be a consequence of student HWI. By exploring both dimensions of student HWI, we have attained the results showing that student HWI-WI directly and positively affects all dimensions of student burnout, while student HWI-TC affects them all indirectly. The most dramatic impact is that of HWI-WI on studies-related burnout, with the standardised coefficient absolute value of 0.999, showing that studies-related burnout increases drastically with the increase of work intensity. All in all, we may say that student time commitment is not a bad phenomenon per se, while student work intensity should be controlled since it can lead to resource depletion (Leiter and Maslach, 2003) and consequently increase burnout levels. We also examined other antecedents of student HWI and burnout, and a conspicuous result to be observed is that the only factor affecting all of the examined variables is the tuition payment source. It probably speaks a lot about still challenging economic situation in Serbia and the need for the introduction of incentives and politics that would, at least to some extent, relieve the burden from the students who self-finance their studies. The other determinant influencing all but one of the variables is student work engagement, a beneficial and health-preserving factor that should be even more worked on and paid attention to by the academic staff.

\section{Contribution to the literature}

Our study finds common factors among previously determined antecedents of heavy work investment (Rabenu, et al., 2019) and student burnout (Maslach, et al., 2001; Palos, Maricuţoiu and Costea, 2019; Yang, 2004; Jackobs and Dodd, 2003; Stoddard, Urban and Schmeiser, 2018; Mastenbroek et al., 2014), further examines and tests them. In addition, the study offers a more detailed insight into the internal, situational and background factors impact on individual burnout scales. The perception of HWI through its two subtypes (time and effort) proposed by Snir and Harpaz (2012) is proven to give a thorough insight into HWI's effects on student burnout. The findings of our study may present the foundations for further research regarding student HWI.

\section{Limitations}

This research is not without limitations. For example, only the students from the state university were included in the research. The results might have been different if the perception of the students from private universities in Serbia was examined. In addition, it was not possible to compare the main results of our study with the outcomes of other studies targeting the same niche, since student HWI is still quite a new topic, unlike student burnout which has already been investigated by other authors. Hence, we compared student HWI findings to the previous ones concerning employees rather than other students.

There are other possible limitations of our study. The most conspicuous question regarding methodology is related to the absence of a significant impact of student work engagement on student work intensity. This is in contrast to other empirical research (Rabenu et al., 2019) that found a positive relation between work engagement and HWI-WI, although in the workplace (not an academic environment). Also, course load has not been found to have an impact on any of the dimensions of burnout, while previous studies suggested that 
workload (equivalent to academic course load) is positively correlated to either some (Male and May, 1998) or all dimensions of burnout (Greenglass, Burke and Fikensbaum, 2001).

\section{Suggestions for future research}

It is our opinion that future research regarding student heavy work investment should be focused on some of the most critical issues connected to the phenomenon: the instrument for student HWI measurement as well as the examination of other potential outcomes and antecedents of student HWI. More specifically, since our study is among pioneer ones in regard to student heavy work investment, we devised a scale for measuring HWI's both dimensions, HWI-WI and HWI-TC. In this respect, we suggest improving the scale or adding other items to it, and testing it consequently. Also, as previous studies have shown a variety of other individual and organisational-level outcomes of employee HWI (Schaufeli et al., 2009; Houlfort et al., 2013; Rabenu et al, 2019), we suggest exploring similar potential outcomes of student HWI, such as student general satisfaction, academic performance, academic performance satisfaction, student retention rates, student absenteeism rates and other health issues apart from burnout. Moreover, since the literature suggests various other internal, situational and background HWI antecedents (Snir and Harpaz, 2012, 2015), we suggest examining those connected to study motivation, personality traits, organisational culture of different faculties, income levels of students' families (if ethically acceptable), age, and the like. Lastly, we propose testing a slightly different model of student HWI, which would examine HWI only as a mediator variable between its antecedents and outcomes. Our intention is to examine the effects of heavy work investment on student performance and student performance satisfaction, as well as to explore coping mechanisms as the moderator variables between student heavy work investment and burnout.

\section{Practical implications}

The results of the current study can be of use to academic staff and university management interested in creating the programmes that promote healthy approaches to learning as well as the programs related to the student burnout prevention. Specifically, those programmes should include the information about the influence of work intensity and work engagement on student burnout, and possibly teach students some good habits that would alleviate the negative effects of heavy work investment, and increase their engagement at the same time. Also, we strongly recommend the introduction of measures which would help the students who pay tuition fees on their own.

\section{References}

Adams, D.R., Meyers, S.A. and Beidas, R.S., 2016. The relationship between financial strain, perceived stress, psychological symptoms, and academic and social integration in undergraduate students. Journal of American College Health, 64(5), pp.362-370.

Alarcón, D. and Sánchez., J. 2015. Assessing convergent and discriminant validity in the ADHD-R IV rating scale: User-written commands for Average Variance Extracted (AVE), Composite Reliability (CR), and Heterotrait-Monotrait ratio of correlations (HTMT). [online] Available at: <https://www.stata.com/meeting/spain15/abstracts/ materials/spain15_alarcon.pdf> [Accessed 4 March 2020]. 
Allen, J., Eboli, L., Forciniti, C., Mazzulla, G. and Ortúzar, J. de D. 2019. The role of critical incidents and involvement in transit satisfaction and loyalty. Transport Policy, 75, pp.57-69.

Anderson, E. D. and Cole, B. S., 1988. Stress factors related to reported academic performance and burnout. Education, 108(4).

Ang, R.P. and Huan, V.S., 2006. Academic expectations stress inventory (AESI): Development, factor analysis, reliability and validity. Educational and Psychological Measurement, 66, pp.522-539.

Asparouhov, T. and Muthén, B., 2009. Exploratory Structural Equation Modeling. Structural Equation Modeling: A Multidisciplinary Journal, 16(3), pp.397-438.

Astakhova, M. and Hogue, M., 2013. A heavy work investment typology: a biopsychosocial framework. Journal of Managerial Psychology, 29(1), pp.81-99.

Babic, A., Stinglhamber, F., Barbier, M. and Hansez, I., 2019. Work environment and work-to-family conflict: examining the mediating role of heavy work investment. Journal of Management \& Organization, [e-journal] pp.1-24. https://doi.org/10.1017/jmo.2019.40.

Backović, D.V., Zivojinović, J.I., Maksimović, J. and Maksimović, M., 2012. Gender differences in academic stress and burnout among medical students in final years of education. Psychiatr Danub, 24(2), pp.175-181.

Bakker, A. B. and Demerouti, E., 2014. Job demands-resources theory. In: P.Y. Chen and C.L. Cooper eds., 2014. Wellbeing: A complete reference guide. Work and wellbeing. S.1: Wiley Blackwell, pp.37-64.

Bakker, A.B., Demerouti, E. and Schaufeli, W.B., 2002. Validation of the Maslach burnout inventory-general survey: An internet study. Anxiety, Stress \& Coping, 15(3), pp.245-260.

Balogun, J.A., Hoeberlein-Miller, T.M., Schneider, E. and Katz, J.S., 1996. Academic performance is not a viable determinant of physical therapy students' burnout. Perceptual and Motor Skills, 83(1), pp.21-22.

Black, A.E. and Deci, E.L., 2000. The effects of instructors' autonomy support and students' autonomous motivation on learning organic chemistry: A self-determination theory perspective. Science education, 84, pp.740-756.

Bowen, W.G., Chingos, M.M. and McPherson, M.S., 2009. Crossing the Finish Line: Completing College at America's Public Universities. Princeton, NJ: Princeton University Press.

Browne, M.W. and Cudeck, R., 1993. Alternative ways of assessing model fit. In: K.A. Bollen and J.S. Long eds., 1993. Testing structural equation models. Newbury Park, CA: Sage, pp.136-162.

Byrd, D.R. and McKinney, K.J., 2012. Individual, interpersonal, and institutional level factors associated with the mental health of college students. Journal of American College Health, 60(3), pp.185-193.

Campos, J., Carlotto, M. and Maroco, J., 2012. Copenhagen Burnout Inventory - Student Version: Adaptation and Transcultural Validation for Portugal and Brazil. Psicologia: Reflexão e Crítica, 26, pp.87-97. 
Carlotto, M.S., Nakamura, A.P. and Câmara, S.G., 2006. Síndrome de Burnout em estudantes universitários da área. Psico, 37(1), p.5.

Carmona-Halty, M.A., Schaufeli, W.B. and Salanova, M., 2019. The utrecht work engagement scale for students (UWES-9S): factorial validity, reliability, and measurement invariance in a chilean sample of undergraduate university students. Frontiers in psychology, [e-journal] p.10. https://doi.org/10.3389/fpsyg.2019.01017.

Case, J., 2008. Alienation and engagement: Development of an alternative theoretical framework for understanding student learning. Higher Education, 55(3), pp.321-332.

Cheng, T. and Selden, M., 1994. The Origins and Social Consequences of China's Hukou System. The China Quarterly, 139, pp.644-668.

Cobb, S. and Rose, R.M., 1973. Hypertension, peptic ulcer, and diabetes in air traffic controllers. Jama, 224(4), pp.489-492.

Cronbach, L.J., 1951. Coefficient alpha and the internal structure of tests. Psychometrika, 16(3), pp.297-334.

Di Stefano, G. and Gaudiino, M., 2019. Workaholism and work engagement: How are they similar? How are they different? A systematic review and meta-analysis. European Journal of Work and Organizational Psychology, 28(3), pp.329-347.

Dogan, U., 2015. Student engagement, academic self-efficacy, and academic motivation as predictors of academic performance. The Anthropologist, 20(3), pp.553-561.

Dusselier, L., Dunn, B., Wang, Y., Shelley, M.C. and Whalen, D.F., 2005. Personal, health, academic, and environmental predictors of stress for residence hall students. Journal of American College Health, 54(1), pp.15-24.

Eremsoy, C.E., Çelimli, S. and Gençöz, T., 2005. Students under academic stress in a Turkish University: variables associated with symptoms of depression and anxiety. Current Psychology, 24, pp.123-133.

Fiksenbaum, L., Jeng, W., Koyuncu, M. and Burke, R., 2010. Work hours, work intensity, satisfactions and psychological well-being among hotel managers in China. Cross Cultural Management: An International Journal, 17, pp.79-93.

Freudenberger, H., 1974. Staff Burnout. Journal of Social Issues, 30, pp.159-165.

González-Romá, V., Schaufeli, W.B., Bakker, A.B. and Lloret, S., 2006. Burnout and work engagement: Independent factors or opposite poles?. Journal of vocational behavior, 68(1), pp.165-174.

Gray, J.A. and DiLoreto, M., 2016. The effects of student engagement, student satisfaction, and perceived learning in online learning environments. International Journal of Educational Leadership Preparation, 11(1).

Green, F., 2008. Work effort and worker well-being in the age of affluence. In: C. Burke ed., 2008. The long work hours culture: Causes, consequences and choices. UK: Emerald Group Publishing, pp.115-135.

Greenglass, E.R., Burke, R.J. and Fiksenbaum, L., 2001. Workload and burnout in nurses. Journal of community \& applied social psychology, 11(3), pp.211-215.

Harpaz, I. and Snir, R. eds., 2015. Applied psychology series. Heavy work investment: Its nature, sources, outcomes, and future directions. S.l: Routledge/Taylor \& Francis Group. 
Harpaz, I. and Snir, R., 2016. Heavy-work investment and its impact on well-being and health: Preliminary results. The Study of Organizations and Human Resource Management Quarterly, 1, pp.6-24.

Hastings, R.P. and Bham, M.S., 2003. The Relationship between Student Behaviour Patterns and Teacher Burnout. School Psychology International, 24(1), pp.115-127.

Hooper, D., Coughlan, J. and Mullen, M.R., 2008. Structural Equation Modelling: Guidelines for Determining Model Fit. Electronic Journal of Business Research Methods, 6(1), pp.53-60.

Houlfort, N., Philippe, F.L., Vallerand, R.J. and Ménard, J., 2014. On passion and heavy work investment: personal and organisational outcomes. Journal of Managerial Psychology, 29(1), pp.25-45.

Hox, J.J. and Bechger, T.M., 1998. An introduction to structural equation modeling. Family Science Review, 11, pp.354-373.

Hsu, L., 2013. Work motivation, job burnout, and employment aspiration in hospitality and tourism students - An exploration using the self-determination theory. Journal of Hospitality, Leisure, Sport \& Tourism Education, 13, pp.180-189.

Huan, V.S., Yeo, L.S., Ang, R.P. and Chong, W.H., 2006. The influence of dispositional optimism and gender on adolescents'perception of academic stress. Adolescence, 41(163).

Isralowitz, R.E. and Hong, O.T., 1990. Singapore youth: The impact of social status on perceptions of adolescent problems. Adolescence, 25(98), p.357.

Ivancevic, S., Vaci, A. and Nisic, A., 2016. Burnout Syndrome. In: s.n., The $1^{\text {st }}$ International Conference 'New Challenges in Education'. Terme Čatež, Slovenia, n.d. s.l: s.n.

Ivanović, T., Ivančević, S. and Maričić, M., 2020. The relationship between Recruiter Burnout, Work Engagement and Turnover Intention: Evidence from Serbia. Engineering Economics, 31(2), pp.197-210.

Ivanovic, T. and Ivancevic, S. (2019). Turnover Intentions and Job Hopping among Millennials in Serbia. Management:Journal Of Sustainable Business And Management Solutions In Emerging Economies, 24(1), 53-63. doi:10.7595/management. fon. 2018.0023

Jacobs, S.R. and Dodd, D., 2003. Student burnout as a function of personality, social support, and workload. Journal of college student development, 44(3), pp.291-303.

Johnson, K.C., 2019. Perceived Stress Among First-Generation African American College Males. Education Doctoral. Paper 415. [online] Available at: <https://fisherpub.sjfc.edu/cgi/viewcontent.cgi?article=1422\&context=education_etd> [Accessed 3 June 2020].

Jose, P. E. and Ratcliffe, V., 2004. Stressor frequency and perceived intensity as predictors of internalizing symptoms: Gender and age differences in adolescence. New Zealand Journal of Psychology, 33(3), p. 145.

Kahn, R.L., Wolfe, D.M., Quinn, R.P., Snoek, J.D. and Rosenthal, R.A., 1964. Organisational stress: Studies in role conflict and ambiguity. S.l: John Wiley. 
Kisch, J., Leino, E.V. and Silverman, M.M., 2005. Aspects of suicidal behavior, depression, and treatment in college students: results from the spring 2000 national college health assessment survey. Suicide Life-Threat, 35(1), pp.3-13.

Kiuru, N., Aunola, K., Nurmi, J.E., Leskinen, E. and Salmela-Aro, K., 2008. Peer group influence and selection in adolescents' school burnout: A longitudinal study. MerrillPalmer Quarterly, (1982), pp.23-55.

Kline, R.B., 2005. Principles and practice of structural equation modelling. $2^{\text {nd }}$ ed. New York: Guilford.

Kristensen, T.S., Borritz, M., Villadsen, E. and Christensen, K.B., 2005. The Copenhagen Burnout Inventory: A new tool for the assessment of burnout. Work \& Stress, 19(3), pp.192-207.

Kusurkar, R.A., Croiset, G., Galindo-Garré, F. and Cate, O.T., 2013. Motivational profiles of medical students: Association with study effort, academic performance and exhaustion. BMC medical education, 13, p.87.

Leiter, M.P. and Maslach, C., 2003. Areas of worklife: A structured approach to organisational predictors of job burnout. Research in occupational stress and well being, 3(1), pp.91-134.

Levesque, C., Zuehlke, A.N., Stanek, L.R. and Ryan, R.M., 2004. Autonomy and competence in German and American university students: A comparative study based on self-determination theory. Journal of Educational Psychology, 96(1), pp.68-84.

Lingard, H., 2003. The impact of individual and job characteristics on "burnout" among civil engineers in Australia and the implications for employee turnover. Construction Management and Economics, 21(1), pp.69-80.

Male, D. and May, D., 1998. Stress and health, workload and burnout in learning support co- ordinators in colleges of further education. Support for Learning, 13, pp.134-138.

Maroco, J. and Tecedeiro, M., 2009. Inventário de Burnout de Maslach para estudantes portugueses. Psicologia, Saúde \& Doenças, 10(2), pp.227-235.

Marsh, H.W., Muthén, B., Asparouhov, T., Lüdtke, O., Robitzsch, A., Morin, A.J.S. and Trautwein, U., 2009. Exploratory Structural Equation Modeling, Integrating CFA and EFA: Application to Students' Evaluations of University Teaching. Structural Equation Modeling: A Multidisciplinary Journal, 16(3), pp.439-476.

Martini, S., Arfken, C.L. and Balon, R., 2006. Comparison of burnout among medical residents before and after the implementation of work hours limits. Academic Psychiatry, 30(4), pp.352-355.

Maslach, C. and Jackson, S.E., 1981. The measurement of experienced burnout. Journal of organisational behavior, 2(2), pp.99-113.

Maslach, C., Jackson, S.E. and Leiter, M.P., 1996. Maslach burnout inventory manual. $3^{\text {rd }}$ ed. Palo Alto, CA: Consulting Psychologists Press.

Maslach, C., Jackson, S.E., Leiter, M.P., Zalaquett, C. and Wood, R., 1997. Evaluating stress: A book of resources. USA: Scarecrow.

Maslach, C. and Leiter, M.P., 1997. The truth about burnout. San Francisco: Jossey Bass.

Maslach, C., Schaufeli, W.B. and Leiter, M.P., 2001. Job burnout. Annual review of psychology, 52(1), pp.397-422. 
Mastenbroek, N.J.J.M., Jaarsma, A.D.C., Demerouti, E., Muijtjens, A.M.M., Scherpbier, A.J.J.A., and van Beukelen, P., 2014 Burnout and engagement, and its predictors in young veterinary professionals: the influence of gender. Veterinary Record, 174, p.144.

McCarthy, M.E., Pretty, G.M. and Catano, V., 1990. Psychological sense of community and student burnout. Journal of college student development, 31(3), pp.211-216.

McNamara, M., Bohle, P. and Quinlan, M., 2011. Precarious employment, working hours, work-life conflict and health in hotel work. Applied Ergonomics, 42(2), pp.225-232.

Milenković, M., Glavić, D. and Maričić, M., 2019. Determining factors affecting congestion pricing acceptability. Transport Policy, 82, pp.58-74.

Moneta, G.B., 2011. Need for achievement, burnout, and intention to leave: Testing an occupational model in educational settings. Personality and Individual Differences, 50(2), pp.274-278.

Murberg, T.A. and Bru, E., 2004. School-related stress and psychosomatic symptoms among Norwegian adolescents. School Psychology International, 25(3), pp.317-332.

Nogueira-Martins, L., Fagnani Neto, R., Macedo, P., Citero, V. and Mari, J., 2004. The mental health of graduate students at the federal university of Sao Paulo: A preliminary report. Brazilian Journal of Medical and Biological Research, 37, pp.1519-1524.

Özdemir, B. and Demir, A., 2019. Romantic relationship satisfaction, age, course load, satisfaction with income and parental status as predictors of instructors' burnout: Evidence from a correlational study. Current Psychology, 38(5), pp.1083-1098.

Paloș, R., Maricuţoiu, L. P. and Costea, I., 2019. Relations between academic performance, student engagement and student burnout: A cross-lagged analysis of a two-wave study. Studies in Educational Evaluation, 60, pp.199-204.

Podsakoff, P. M., MacKenzie, S. B., Lee, J. Y. and Podsakoff, N. P., 2003. Common method biases in behavioral research: a critical review of the literature and recommended remedies. Journal of applied psychology, 88(5), p. 879.

Preacher, K.J. and Hayes, A.F., 2008. Asymptotic and resampling strategies for assessing and comparing indirect effects in multiple mediator models. Behavior Research Methods, 40(3), pp.879-891.

Purvanova, R.K. and Muros, J.P., 2010. Gender differences in burnout: A meta-analysis. Journal of vocational behavior, 77(2), pp.168-185.

Rabenu, E. and Aharoni-Goldenberg, S., 2017. Understanding the relationship between overtime and burnout. International Studies of Management \& Organization, 47(4), pp.324-335.

Rabenu, E., Shkoler, O., Lebron, M.J. and Tabak, F., 2019. Heavy-work investment, job engagement, managerial role, person-organisation value congruence, and burnout: A moderated-mediation analysis in USA and Israel. Current Psychology, pp.1-18.

Ramist, L., 1981. College student attrition and retention. New York: College Entrance Examination Board.

Raychaudhuri, A., Debnath, M., Sen, S. and Majundra, B.G., 2010. Factors affecting Student's academic performance: A case study in agartala municipal concial area. Bangladesh e-journal of Sociology, 7(2), pp.34-41. 
Richards, K.A.R., Levesque-Bristol, C., Templin, T.J. and Graber, K.C., 2016. The impact of resilience on role stressors and burnout in elementary and secondary teachers. Social Psychology of Education, 19(3), pp.511-536.

Salanova, M., Schaufeli, W., Martínez, I. and Bresó, E., 2010. How obstacles and facilitators predict academic performance: The mediating role of study burnout and engagement. Anxiety, stress \& coping, 23(1), pp.53-70.

Salanova, M., Del Líbano, M., Llorens, S. and Schaufeli, W.B., 2014. Engaged, workaholic, burned-out or just 9-to-5? Toward a typology of employee well-being. Stress Health, 30(1), pp.71-81.

Salmela-Aro, K., Savolainen, H. and Holopainen, L., 2009. Depressive symptoms and school burnout during adolescence: Evidence from two cross-lagged longitudinal studies. Journal of youth and adolescence, 38(10), pp.1316-1327.

Sansgiry, S.S. and Sail, K., 2006. Effect of students' perceptions of course load on test anxiety. American journal of pharmaceutical education, 70(2), p.26.

Schaufeli, W.B., 2016. Heavy work investment, personality and organisational climate. Journal of Managerial Psychology, 31(6), pp.1057-1073.

Schaufeli, W.B. and Bakker, A.B., 2004. Job demands, job resources, and their relationship with burnout and engagement: A multi- sample study. Journal of Organizational Behavior: The International Journal of Industrial, Occupational and Organisational Psychology and Behavior, 25(3), pp.293-315.

Schaufeli, W.B. and Bakker, A.B., 2010. The conceptualisation and measurement of work engagement. In: A.B. Bakker and M.P. Leiter eds., 2010. Work engagement: A handbook of essential theory and research. New York: Routledge.

Schaufeli, W.B., Martinez, I.M., Pinto, A.M., Salanova, M. and Bakker, A.B., 2002. Burnout and engagement in university students: A cross-national study. Journal of cross-cultural psychology, 33(5), pp.464-481.

Schaufeli, W.B., Taris, T.W. and Van Rhenen, W., 2008. Workaholism, burnout, and work engagement: Three of a kind or three different kinds of employee well- being?. Applied psychology, 57(2), pp.173-203.

Schaufeli, W. and Salanova, M., 2007. Work engagement: An emerging psychological concept and its implications for organisations. In: S.W. Gilliland, D.D. Steiner and D.P. Skarlicki eds., 2007. Research in social issues in management (Volume 5): Managing social and ethical issues in organisations. Greenwich, CT: Information Age Publishers. pp.135-177.

Shimazu, A., Schaufeli, W., Kamiyama, K. and Kawakami, N., 2015. Workaholism vs. Work Engagement: the Two Different Predictors of Future Well-being and Performance. International journal of behavioral medicine, 22, pp.18-23.

Shin, H., Lee, J., Kim, B. and Lee, S.M., 2012. Students' perceptions of parental bonding styles and their academic burnout. Asia Pacific Education Review, 13(3), pp.509-517.

Snir, R. and Harpaz, I. 2012. Beyond workaholism: Towards a general model of heavy work investment. Human resource management review, 22(3), pp.232-243.

Snir, R. and Harpaz, I., 2015. A general model of heavy work investment: Introduction. In: I. Harpaz and R. Snir eds., 2015. Applied psychology series. Heavy work investment: Its 
nature, sources, outcomes, and future directions. S.l: Routledge/Taylor \& Francis Group. pp.3-30.

Stoddard, C., Urban, C. and Schmeiser, M.D., 2018. College financing choices and academic performance. Journal of Consumer Affairs, 52(3), pp.540-561.

Taris, T. W., Van Beek, I. and Schaufeli, W.B. 2015. The beauty versus the beast: On the motives of engaged and workaholic employees. In: I. Harpaz and R. Snir eds., 2015. Heavy work investment: Its nature, sources, outcomes, and future directions. New York, NY: Taylor \& Francis, pp.121-138.

Tavakol, M. and Dennick, R., 2011. Making sense of Cronbach's alpha. International Journal of Medical Education, 2, pp.53-55.

Tessema, M., Ready, K. and Malone, C., 2012. Effect of gender on college students' satisfaction and achievement: The case of a midsized Midwestern public university. International Journal of Business and Social Science, 3(10, pp.1-11.

University of Belgrade, 2020. Izveštaj univerzitetske komisije za upis studenata u prvu godinu studijskih programa. [pdf] Belgrade. Available at: <http://www.bg.ac.rs/files/sr/ studije/Analiza_upisa_OAS_IAS_OSS_2019-2020.pdf> [Accessed 10 September 2020].

Upadyaya, K. and Salmela-Aro, K., 2013. Development of school engagement in association with academic success and well-being in varying social contexts: A review of empirical research. European Psychologist, 18(2), p.136.

van Beek, I., 2014. Understanding the dark and bright sides of heavy work investment: Psychological studies on workaholism and work engagement. PhD. Utrecht University.

van Beek, I., Taris, T.W. and Schaufeli, W.B., 2011. Workaholic and work engaged employees: Dead ringers or worlds apart? Journal of Occupational Health Psychology, 16(4), pp.468-482.

Van Beek, I.W., Taris, T.B., Schaufeli, W. and Brenninkmeijer, V., 2013. Heavy work investment: its motivational make-up and outcomes. Journal of Managerial Psychology, 29(1), pp.46-62.

Williams, C. J., Dziurawiec, S. and Heritage, B., 2018. More pain than gain: Effort-reward imbalance, burnout, and withdrawal intentions within a university student population. Journal of Educational Psychology, 110(3), p.378.

Yang, H.J., 2004. Factors affecting student burnout and academic achievement in multiple enrollment programs in Taiwan's technical-vocational colleges. International Journal of Educational Development, 24(3), pp.283-301.

Yang, H.J. and Farn, C.K., 2005. An investigation the factors affecting MIS student burnout in technical-vocational college. Computers in human behavior, 21(6), pp.917-932. 